\title{
BMJ Open PIPc study: development of indicators of potentially inappropriate prescribing in children (PIPc) in primary care using a modified Delphi technique
}

\author{
Emma Barry, ${ }^{1}$ Kirsty O’Brien, ${ }^{1}$ Frank Moriarty, ${ }^{1}$ Janine Cooper ${ }^{2}$ Patrick Redmond, ${ }^{1}$ \\ Carmel M Hughes, ${ }^{2}$ Kathleen Bennett, ${ }^{1}$ Tom Fahey, ${ }^{1}$ Susan M Smith, ${ }^{1}$ \\ The PIPc Project Steering group
}

To cite: Barry E, O'Brien K, Moriarty F, et al. PIPc study: development of indicators of potentially inappropriate prescribing in children (PIPc) in primary care using a modified Delphi technique. BMJ Open 2016;6:e012079. doi:10.1136/bmjopen-2016012079

- Prepublication history and additional material is available. To view please visit the journal (http://dx.doi.org/ 10.1136/bmjopen-2016012079).

Received 28 March 2016 Revised 31 May 2016 Accepted 1 July 2016

CrossMark

\begin{abstract}
${ }^{1}$ Department of General Practice, HRB Centre for Primary Care Research, Royal College of Surgeons in Ireland, Dublin, Ireland ${ }^{2}$ Clinical and Practice Research Group, School of Pharmacy, Queen's University Belfast, Belfast, UK
\end{abstract}

Correspondence to Professor Susan M Smith; susansmith@rcsi.ie

\section{ABSTRACT}

Objective: There is limited evidence regarding the quality of prescribing for children in primary care. Several prescribing criteria (indicators) have been developed to assess the appropriateness of prescribing in older and middle-aged adults but few are relevant to children. The objective of this study was to develop a set of prescribing indicators that can be applied to prescribing or dispensing data sets to determine the prevalence of potentially inappropriate prescribing in children (PIPc) in primary care settings.

Design: Two-round modified Delphi consensus method.

Setting: Irish and UK general practice.

Participants: A project steering group consisting of academic and clinical general practitioners (GPs) and pharmacists was formed to develop a list of indicators from literature review and clinical expertise. 15 experts consisting of GPs, pharmacists and paediatricians from the Republic of Ireland and the UK formed the Delphi panel.

Results: 47 indicators were reviewed by the project steering group and 16 were presented to the Delphi panel. In the first round of this exercise, consensus was achieved on nine of these indicators. Of the remaining seven indicators, two were removed following review of expert panel comments and discussion of the project steering group. The second round of the Delphi process focused on the remaining five indicators, which were amended based on first round feedback. Three indicators were accepted following the second round of the Delphi process and the remaining two indicators were removed. The final list consisted of 12 indicators categorised by respiratory system $(n=6)$, gastrointestinal system $(n=2)$, neurological system $(n=2)$ and dermatological system $(\mathrm{n}=2)$.

Conclusions: The PIPc indicators are a set of prescribing criteria developed for use in children in primary care in the absence of clinical information. The utility of these criteria will be tested in further studies using prescribing databases.

\section{Strengths and limitations of this study}

- The members of Delphi panel in this study were heterogeneous in experience and setting, and represented the professions involved in prescribing and dispensing to children.

- The Delphi process used in the study followed predefined methodology in line with best practice.

- Dispensing databases may not contain clinical information, limiting the application of indicators that require such information for interpretation.

- The reliability of the Delphi technique as a method for achieving consensus has been debated but its potential limitations are similar to other consensus techniques.

\section{BACKGROUND}

Quality of prescribing for children has been identified as an area of concern since the late 1970 's, when it was reported that $60 \%$ of children under 14 years received at least one prescription a year from their family practitioner. $^{1}$ Currently, children represent over $25 \%$ of the population and receive an average of three prescription medications before 5 years of age. ${ }^{2}$ There are ongoing concerns over the quality of prescribing for children, but there is a lack of studies in this area. ${ }^{3}$ Potential consequences for children may be adverse drug events leading to unplanned hospital admissions and preventable deaths. ${ }^{4}$

Medicines are generally considered appropriate in an adult population when they have a clear evidence-based indication, are well tolerated in the majority of patients and are cost effective. ${ }^{5}$ Medicines or prescribing patterns that do not fit this description can be considered inappropriate; this term includes 
misprescribing, underprescribing and overprescribing. ${ }^{6}$ Misprescribing includes the incorrect prescription of an indicated medication and can be divided into drug choice, dosage, duration of therapy, duplication of drugs of the pharmacological class and drug-disease or drugdrug interactions or drug-food interactions. Underprescribing includes the omission of a prescription that is needed and overprescribing; the prescription of a medication that is unnecessary. ${ }^{7}$ The term "potentially inappropriate prescribing' acknowledges the reality of prescribing in clinical practice, whereby the prescription of an inappropriate medication may be justified by the individual needs of a particular patient. ${ }^{8}$ For example, sedating antihistamines may be considered inappropriate for young children because of the risk of side effects such as sedation, paradoxical excitation and potential cardiac toxicity. However, they may, in some instances, be useful in the treatment of insomnia relating to itch caused by eczema.

Research into potentially inappropriate prescribing in adults has focused on the development of indicators or explicit criteria of prescribing, which are measurable criteria against which quality standards can be set and audited. Explicit indicators, such as the Screening Tool to Alert doctors to the Right Treatment/Screening Tool of Older Peoples' potentially inappropriate Prescriptions (START/STOPP) criteria, were devised to identify PIP in older adults and have been found to be valid, reliable and generalisable across international primary care settings. ${ }^{9}$

To date, many quality indicators of care of children in primary care relate to specific diseases or conditions such as mental health or diabetes. ${ }^{10}{ }^{11}$ More recent work in France has led to the development of the first set of indicators of inappropriate prescribing in children for use in hospital and community settings. ${ }^{12}$ Researchers in the UK have also developed primary care quality indicators for children that include some prescribing indicators but focus on broader issues such as the management and assessment of clinical conditions, child development and child protection. ${ }^{13}$ Other criteria have been developed for use in the out-of-hours setting and in paediatric emergency departments. ${ }^{14} 15$

Recent studies have highlighted that explicit prescribing indicators are not sufficient to assess whether prescribing is appropriate or not in the context of assessing daily prescribing practices. ${ }^{16}$ Ideally, a prescribing indicator would be based on a thorough review of patient records with access to the full clinical and treatment history of the patient. Nonetheless, this process is time consuming and can be extremely complex. ${ }^{17}{ }^{18}$ Although the evidence base for developing explicit prescribing indicators is limited, combining expert professional opinion with consensus methodology can create quality indicators in areas where it would not otherwise be possible. ${ }^{19}$ Explicit indicators can be useful in assessing the quality of prescribing using large national prescribing databases without clinical information. ${ }^{20}$
This study aims to create indicators that are based on commonly prescribed medications to children in primary care and are supported by international best practice guidelines.

\section{METHOD}

\section{Study design}

A modified Delphi consensus technique was used to develop these prescribing criteria. This technique allows an estimate of an overall group opinion to be reached by improving agreement between a panel of experts through rounds of questionnaires. ${ }^{21}$ The Delphi panel was modified as direct feedback would not be provided to the Delphi panel members between rounds. Ethical approval for this study was obtained from the Royal College of Surgeons in Ireland (RCSI) Research Ethics Committee, Dublin, Ireland in April 2014.

\section{Compilation of initial indicators}

We undertook a comprehensive literature search using PubMed to identify any previously developed indicators relating to potentially inappropriate prescribing in children (PIPc). Online supplementary file 1 shows the search string used. As very few indicators from lists devised for adults or older adults are applicable to children, the search strategy was limited to include only those articles involving infants, children or adolescents. The search was performed initially in April 2014 and updated in August 2015.

A set of initial indicators were identified from the literature search. Clinical guidelines, web sources and PubMed were used to identify the best available evidence to support each indicator. Online supplementary file 2 details a full list of information sources used. The British National Formulary for Children $(\mathrm{BNFc})^{22}$ and the Irish Medicines Formulary (IMF) ${ }^{23}$ were used as reference resources for indication, dosages and licensing information.

A project steering group was formed to guide the development of the indicators using predefined inclusion and exclusion criteria. The steering group consisted of academic/clinical general practitioners (GPs), three academic/clinical pharmacists, a pharmacoepidemiologist/statistician and a postdoctoral researcher, all members of either the HRB Centre for Primary Care Research at the RCSI Dublin or the School of Pharmacy at Queen's University Belfast.

Inclusion criteria are as follows: indicators had to:

- describe a pattern of prescribing that was potentially hazardous or known to be ineffective

- describe a pattern of prescribing that was not in keeping with best practice or current guidelines

- apply to the population of interest; children $<16$ years Exclusion criteria are as follows:

- medications currently unavailable in the study setting

- criteria which could not be applied in the absence of clinical information 
- criteria containing medications with a low prevalence of use (to define uncommon use, a cut-off of $<0.5$ / 1000 General Medical Scheme (GMS) patients was agreed by the project steering group)

Members of the project steering group applied the inclusion and exclusion criteria and examined the evidence supporting each indicator. For example, the criterion 'Fluoxetine is the most appropriate antidepressant for children, other SSRIs should not be prescribed' was removed by the project steering group during this screening stage as the criterion related specifically to patients with depression and could not be successfully applied in the absence of clinical information. Some criteria identified from literature were modified by the project steering group to make them applicable to dispensing database without clinical information, for example, 'Children with eczema should be prescribed an emollient' was altered to 'An emollient should be prescribed to children who are prescribed greater than one topical corticosteroid in a year', where the prescription of greater than one topical corticosteroid in a year was considered a proxy for a diagnosis of eczema. Supplementary file 3 details the indicators removed and the reasons for exclusion by the project steering group.

\section{The primary care reimbursement service database (PCRS)}

The prevalence of individual drug use in children in 2011 was determined using dispensing data from the Health Service Executive-Primary Care Reimbursement Service (HSE-PCRS). The PCRS is a national dispensing database in Ireland; it stores information on all medications and other health services, provided without charge to people eligible for free medical services in Ireland under the GMS. Eligibility for free medical care is established via means testing and therefore the data collected by the PCRS is not fully representative of the entire population of Ireland. Approximately 39\% (414 856) of the total population $(1072220)$ of children $<16$ years in the Republic of Ireland were eligible for the scheme in 2014. The PCRS contains data on prescriptions originating in primary and secondary care for all children who are eligible for free medical services. Children who receive a prescription from a hospital specialist will have their prescription transcribed to a GMS prescription by their GP in order to avail of free medication. The PCRS does not record data on whether a prescription has originated in primary or secondary care. An Anatomical Therapeutic Chemical Classification System (ATC) code was assigned to each indicator to allow for extraction from the dispensing database.

\section{Selection of the Delphi panel}

In total, 30 specialists from the UK and Republic of Ireland were invited a priori (via email) to participate in a Delphi panel to develop these criteria. Although no specific standard was applied to define an expert, the specialists invited to participate on the panel were peer recognised as experts in their fields by the project steering group and consisted of academic and clinical GPs, paediatricians and pharmacists. A total of 18 specialists agreed to participate. The panel consisted of nine experts from the Republic of Ireland (three GPs, three paediatricians, three pharmacists) and nine from the UK (three GPs three paediatricians, three pharmacists). Written consent was received before starting the process.

\section{Data collection and analysis}

The consensus process involved two rounds of web-based questionnaires. The questionnaire was piloted among the project steering group and GP members of the Department of General Practice, RCSI with minor modifications made subsequently. The first and second rounds of the questionnaires were sent to the Delphi panel between January 2015 and May 2015 and between June 2015 and July 2015, respectively. For each round, panel members were emailed a link to a questionnaire which was maintained on an online survey software tool (SurveyGizmo). Panellists were presented with each indicator and an accompanying rationale for the indicator, categorised by physiological systems (gastrointestinal system, respiratory system, central nervous system, dermatological system) along with a hyperlink to a supporting evidence resource, for example, Cochrane systematic review, the BNFc or national or international guidelines. Panellists were asked to indicate their level of agreement with each indicator using a five-point Likert scale, ${ }^{24}$ (where 1 was strongly disagree and 5 was strongly agree) and to provide comments within a free text box.

Following completion of the first round of questionnaires, the median response and the IQR for each indicator were calculated from the Likert scale. The level required for consensus between the panel members was decided prior to starting the study. When the upper quartile was $\leq 2$, this indicated there was consensus by the Delphi panel members on rejection of the indicator. When the lower quartile was $\geq 4$, this indicated there was consensus by the Delphi panel members on acceptance of the indicator. When the IQR included 3, this indicated there was a lack of agreement between the panel members and a need for further review of the particular indicator. These indicators were reviewed by project steering group and were either revised and included in the second questionnaire or rejected based on the comments received from the Delphi panel. Panellists did not receive feedback from the first questionnaire. The second questionnaire was presented in the same format as the first. Again, the median response and the IQR were calculated, and the project steering group reviewed these measures of agreement along with any additional comments. If consensus was not reached following the second round, the criterion was rejected.

\section{RESULTS}

Figure 1 summarises the development of the indicators. Literature searches identified 47 potential indicators. 


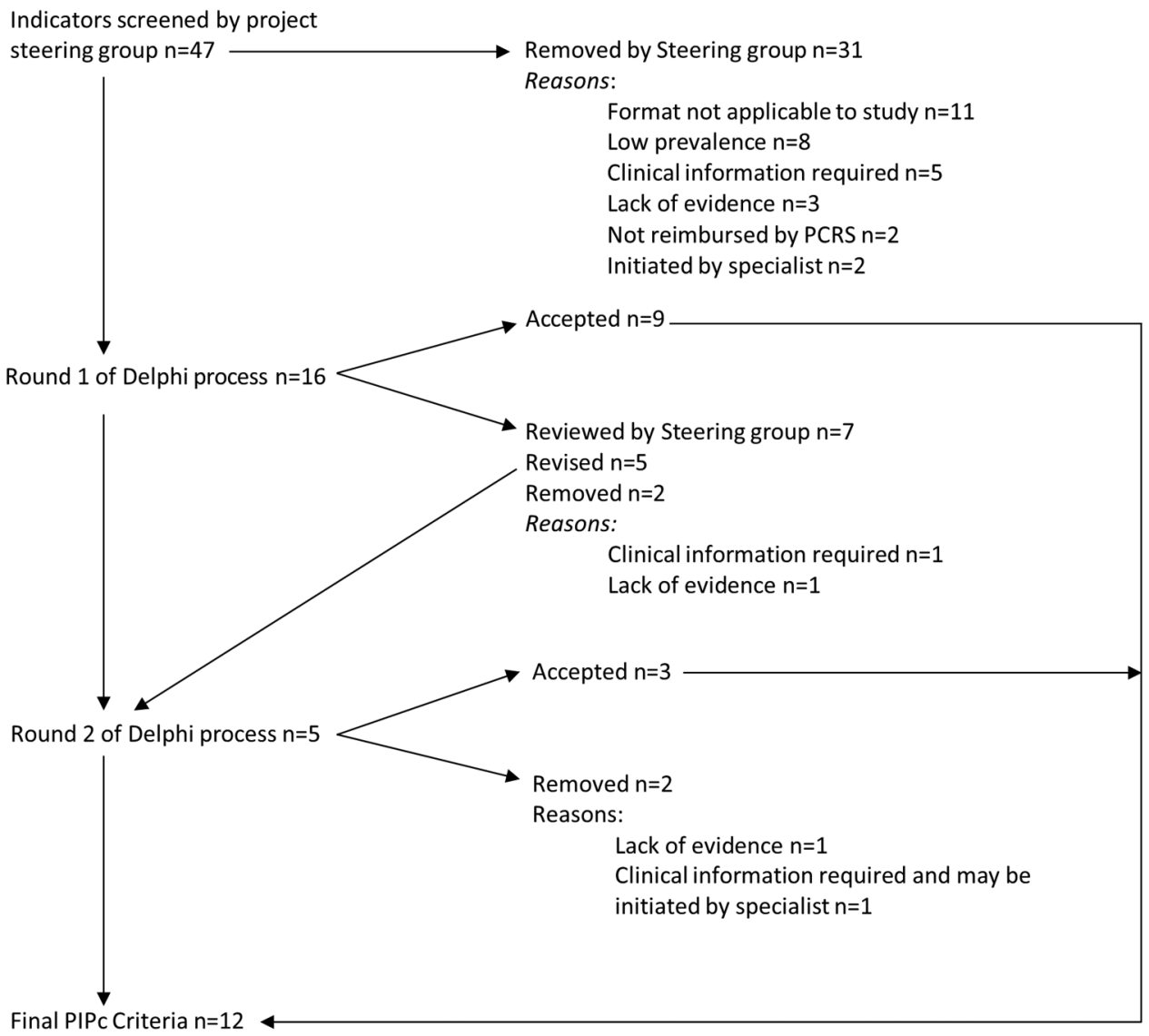

Out of the total identified, 31 indicators were removed following the application of the inclusion and exclusion criteria along with a detailed examination of the evidence by the project steering group. Remaining 16 indicators were presented to the Delphi panel in the first round. Out of 18, 15 experts who consented to participate completed each round of the questionnaire. Three experts did not complete either round. Consensus was reached for nine indicators on the first round with no indicators being rejected; consensus was not reached on seven indicators. From these seven indicators, two were rejected by the project steering group on the basis of the clinical comments of the Delphi panel. Five indicators were then presented to the Delphi panel in round two. Consensus was reached on three indicators and none was rejected outright. Consensus was not reached on the remaining two indicators which were then removed by the project steering group, following review of the comments of the Delphi panel. Table 1 summarises the progression of the indicators through the Delphi process and table 2 provides an example of some of the comments of the Delphi panel.

\section{DISCUSSION}

We have developed a set of twelve indicators of potentially inappropriate prescribing for use in children in primary care through a modified Delphi method. These
12 indicators can be easily and quickly applied to large prescribing or dispensing data sets in the absence of clinical information. The indicators developed in this study were not designed as an exhaustive list of PIPc, but rather represent a list of commonly prescribed medications in Ireland and the UK, which may be used to explore the prevalence of PIPc. The usefulness and validity of these indicators will be investigated in future studies using national prescription-based databases.

\section{Comparison with existing literature}

Concerns about the quality of care received by children in the USA were highlighted in a large study in 2007, which examined the management of common medical conditions in primary care using 175 quality indicators applied to the medical records of 1536 children. $^{3}$ A screening tool consisting of 104 explicit criteria for identifying the omission of prescriptions and inappropriate prescriptions (POPI) in children has recently been developed in France using a Delphi process. ${ }^{12}$ The POPI tool includes propositions or indicators of inappropriate prescribing including omissions of prescribing in the treatment of commonly encountered paediatric health problems, for example, management of pain and fever. Although intended for community and hospital settings, this tool was developed without the input of GPs and has not yet been validated. ${ }^{12} \mathrm{~A}$ set of 35 primary care 
Table 1 Progression of indicators through the Delphi process

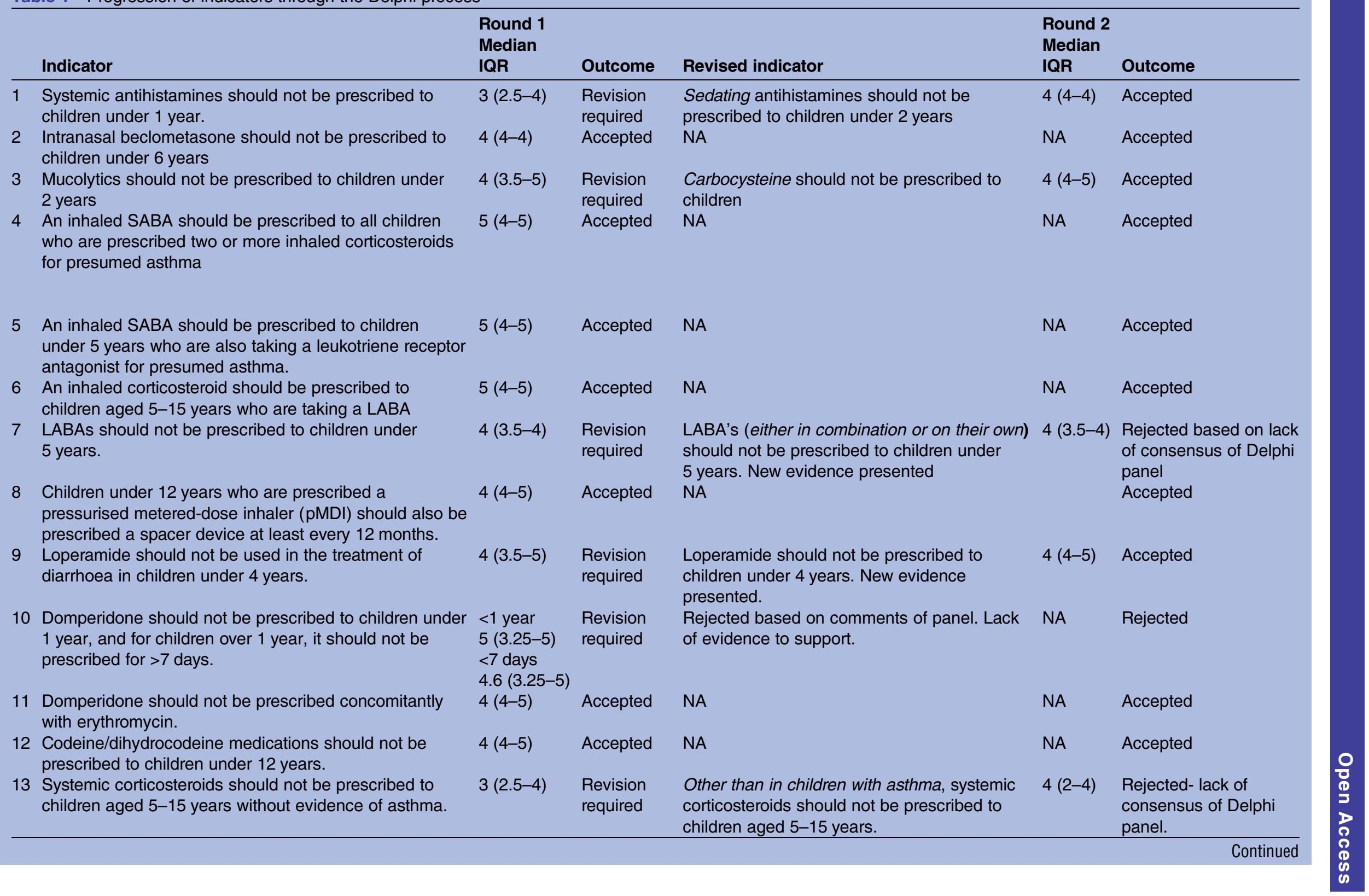




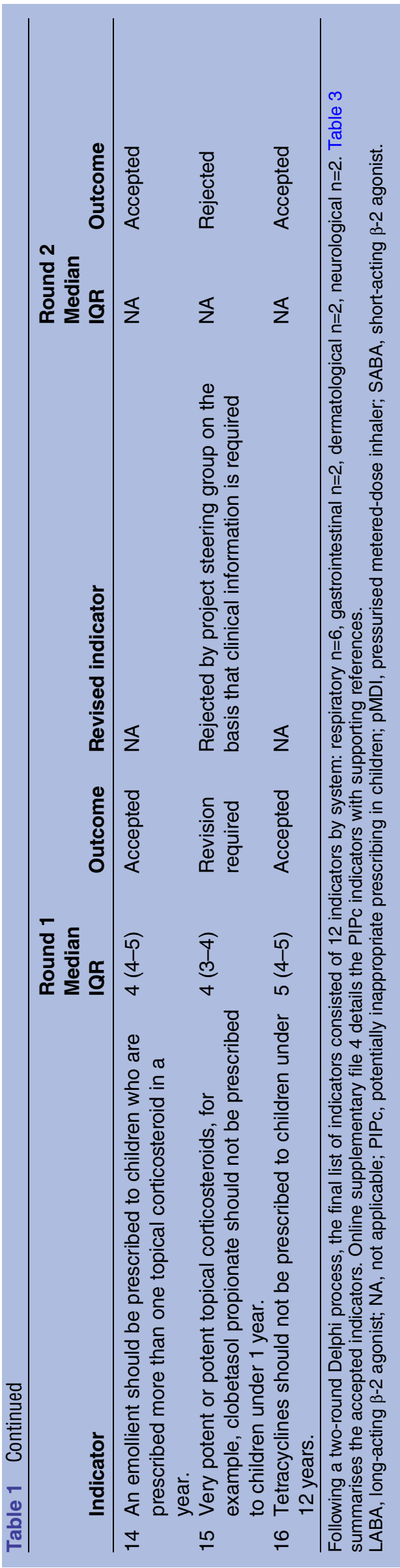

quality indicators for children were also developed in the UK in 2014 using a multistep consensus methodology. ${ }^{13}$ These quality indicators are based on routine and chronic care in addition to child development and child protection and include six prescribing indicators of a total number of 35 indicators overall. There is an overlap between two of these prescribing indicators and the indicators developed in this study. "Children with asthma should be prescribed a spacer' and 'Children with atopic eczema should be prescribed emollients' overlap in both studies. However, in the UK study clinical and diagnostic information is required to implement the indicators, which were designed for auditing computerised primary care records, which contain codes for clinical conditions and have yet to be validated. ${ }^{13} \mathrm{~A}$ cross-sectional study performed in the Netherlands in 2007 examined prescribing and referral in a single out-of-hours setting using 24 indicators developed from national guidelines and a GP expert panel. ${ }^{14}$ These indicators focused on drug choice, primarily antibiotics, in the management of infections. In our study indicators relating to antibiotic prescribing were excluded as clinical information is required to determine the appropriateness of choice of antibiotic. Nonetheless, our indicators remain relevant to general practice as they relate to commonly prescribed medications such as antiasthmatics. The largest cohort study to date of drug use in children in Europe found that antifectives, respiratory drugs and dermatological agents had the highest prevalence of use across all age groups of children. ${ }^{25}$

\section{Strengths and limitations}

This study followed a well-defined process that has been refined by others in the development of similar criteria in populations other than children, for example, The START/STOPP criteria for detection of PIP in older adults and the PRescribing Optimally in Middle-aged People's Treatment (PROMPT) criteria for detection of PIP in middle-aged adults. ${ }^{9}{ }^{26}$ The PIPc criteria were constructed from two sources-a literature search and the expertise of the project steering group whose members had experience in clinical medicine in primary care settings and in the development of quality indicators of prescribing in other population groups. A second strength was the broad and representative sample of medical professionals involved in paediatric prescribing on the Delphi panel. The panel members were distributed across academic and clinical experience in specialities, such as paediatrics, general practice and pharmacy, providing a high level of (face) validity to the process and were representative of geographically diverse areas of Ireland and the UK. Out of 18, 15 members who agreed to participate completed both rounds of the questionnaires. The number of rounds and consensus method were decided in advance of questionnaire distribution with predefined limits for the acceptance, revision or rejection of indicators. Feedback was not provided to the panellists between rounds in 
Table 2 Exemplar comments received from the Delphi panel on rejected indicators

\section{Rejected following round 1 Indicator Rationale}

Domperidone should not be prescribed to children under 1 year, and for children over 1 year, it should not be prescribed for more than 7 days.

Efficacy in GORD and gastroenteritis is uncertain in this age group. Extrapyramidal side effects occur in young children. Can be used for short-term treatment of nausea and vomiting, maximum duration of use should not normally exceed 1 week.

\section{Very potent or potent topical corticosteroids should not} be prescribed to children under 1 year

Topical corticosteroids can cause adrenal suppression and Cushing's syndrome.

\section{Comments}

'domperidone is not evidence based for little ones' 'would not prescribe... because of risk of extrapyramidal side effects'

'have used this longer term in many cases with no adverse effects But am aware of recent questions'

'efficacy of this drug is unproven, any drug which may mask symptoms or disease progression should never be prescribed for apparent gastroenteritis'

'occasional use necessary- if a child can't sleep won't grow...'

'very rare situations this might be appropriate'

'agree unless prescribed by a consultant'

'if child has severe eczema they may be needed for a short period of time'

'possibly under dermatology guidance for rare severe eczema'

\section{Rejected following round 2}

Indicator Rationale

\section{Comments}

\section{Other than in children with asthma, systemic} corticosteroids should not be prescribed to children aged 5-15 years.

Systemic corticosteroids can cause serious side effects including adrenal suppression, immunosuppression and mood disturbances. In the general paediatric population, there are few indications for systemic corticosteroids apart from asthma and croup. Croup commonly affects children under 5 years Long-acting $\beta$ agonists (LABAs) should not be prescribed to children under 5 years.

Use of LABAs is associated with increased risk of asthma exacerbations, hospitalisations and asthma-related deaths in children and adults. It is not known if combination use with inhaled corticosteroids reduces this risk.
'Agree unless there is a clinical indication such as flare of juvenile rheumatoid arthritis'

'Exceptions being serious diseases where specialists might prescribe. e.g, glomerulonephritis'

'there are relatively rare indications for systemic steroids in children- they would always be initiated by a specialist"

\section{'Not recommended by the British thoracic guidelines in} under 5 's'

'Lack of fear of their pernicious side effects plus a lack of understanding of the definition of asthma is to blame' 'The Cochrane review summary that is attached says that $\angle A B A$ does not significantly decrease exacerbations or hospitalisations as opposed to your statement of increasing the risk based on the SMART trial'

'I have seen evidence of poor response to short acting bronchodilators in those on long acting bronchodilators'

GORD, Gastro-oesophageal reflux disease; LABA, long-acting $\beta$ agonists; SMART, Salmeterol Multicenter Asthma Research.

order to remove any potential bias of panellists altering their responses to fit those of the groups. The Delphi consensus method allowed the expert panel members to inform the development of these criteria through their level of agreement and additional comments. Some criteria were rejected by the panellists due to the difficulty in determining the appropriateness of a prescribed medication without knowledge of whether a treatment had been initiated by a specialist. Medications which were considered to be appropriate "under specialist supervision only' were therefore removed. Finally, to ensure relevance to clinical general practice each indicator was presented with a clear rationale that described either a lack of clinical effectiveness or the potential serious side effects of the relevant medication. The rationale for the indicator was supported by the highest level of evidence available, provided to the panel in an easily accessible format to facilitate informed decision-making.

The main limitation of this study relates to use of the Delphi technique. While it is a commonly used technique, the reliability of the Delphi method for achieving consensus has been debated in the literature. The information gathered using a Delphi method represents the views of chosen experts about a specific practice at a given time and this may vary depending on the experts involved. ${ }^{27}$ In this study, a panel size of 15 experts with clinical and academic expertise in prescribing to children was used to mitigate this limitation. This is thought to be a sufficient panel size when the experts have a similar training and general understanding of the field of interest. ${ }^{28}$ Ideally, the level of expertise required to be a member of the Delphi panel would be clearly defined prior to the beginning of the study. ${ }^{28}$ Nonetheless, 
Table 3 Accepted indicators

Respiratory system

1 Intranasal beclometasone should not be prescribed to children under 6 years.

2 Carbocisteine should not be prescribed to children

3 An inhaled short-acting $\beta-2$ agonist should be prescribed to all children who are prescribed two or more inhaled corticosteroids for presumed asthma

4 An inhaled short-acting $\beta-2$ agonist should be prescribed to children under 5 years who are also taking a leukotriene receptor antagonist for presumed asthma.

5 An inhaled corticosteroid should be prescribed to children aged $5-15$ years, who are taking a long acting $\beta$-2 agonist (LABA)

6 Children under 12 years who are prescribed a pressurised metered-dose inhaler (pMDI) should also be prescribed a spacer device at least every 12 months

Gastrointestinal System

7 Loperamide should not be prescribed to children under 4 years.

8 Domperidone should not be prescribed concomitantly with erythromycin.

Dermatological system

9 An emollient should be prescribed to children who are prescribed greater than one topical corticosteroid in a year.

10 Tetracyclines should not be prescribed to children under 12 years.

Neurological system

11 Codeine/dihydrocodeine medications should not be prescribed to children under 12 years.

12 Sedating antihistamines should not be prescribed to children under 2 years.

LABA, long-acting $\beta$-2 agonist; pMDI, pressurised metered-dose inhaler.

significant efforts were made to ensure that the Delphi panel were heterogeneous in experience and setting to limit this potential bias. There may be variation in knowledge underpinning panel members' views, but the Delphi panel was provided with the best available evidence to mitigate this effect. It may have been useful to provide the panel with a more objective rating of the evidence, for example using the GRADE system to further aid decision-making, but this was beyond the scope of the current study. ${ }^{29}$

Explicit prescribing criteria are limited in that they do not address individual differences among patients or the complexity or appropriateness of entire medication regimens. ${ }^{30}$ Furthermore, they need to be regularly updated in line with evidence, and country-specific adaptations are necessary where countries differ in their guidelines, standards and approved medications.

Finally, the database used in this study to determine the prevalence of the indicators is not fully representative of the entire population of children in Ireland. The PCRS database contains information on prescriptions dispensed under the means-tested GMS scheme for which $\sim 39 \%$ of the population under 16 years were eligible in 2014. Poorer health has been reported in socioeconomically deprived areas ${ }^{31}$ with an increased prevalence of prescribing; therefore, the use of this database would have inflated the prevalence of prescribing, thus mitigating against the effects of this potential source of bias. Unfortunately data on non-eligible patients are not routinely collected in the Republic of Ireland.

\section{Implications for research and practice}

The examination of individual clinical information to assess the appropriateness of prescribing can be timeconsuming and difficult. These indicators can be applied quickly and easily to large population-based data sets in the absence of clinical information to identify PIPc unexamined to date. A study to validate the indicators developed in this study is currently underway using the PCRS database. Changes and unwarranted variation in prescribing patterns can be identified across time and geographical area. Researchers in other countries outside of Ireland and the UK could use these indicators with translation and some modifications based on country-specific guidelines, clinical practices and drug formularies. ${ }^{7}$ The indicators can be used to examine the impact of changes in guidelines on prescribing patterns on a population level, for example asthma care. The cost of PIPc can also be examined.

The indicators may be used as a screening tool at the level of individual clinical practices and could be used to support detailed medication review of individual patients. Community pharmacists, who routinely dispense medications without clinical information, could also use these indicators as a resource for clinically checking prescriptions for children.

Identification and quantification of PIP in older populations has led to the development of interventions that improve prescribing. For example, a randomised controlled trial of a multifaceted intervention which included pharmacist advice, web-based pharmaceutical treatment algorithms and tailored patient information leaflets had a positive effect on PIP in older populations. ${ }^{32}$ Integrating some of these supports into clinical decision support systems may prove to be a practical method of improving PIPc.

\section{CONCLUSION}

To date, research into paediatric prescribing in primary care is lacking. This study offers a set of 12 evidencebased explicit prescribing indicators to identify PIPc in primary care. The application of these indicators will enable investigation of the prevalence of PIPc and allow examination of changes in PIPc over time.

Twitter Follow the HRB Centre for Primary Care Research at $@$ HRBPrimaryCare

Acknowledgements The authors would like to gratefully acknowledge the members of the Delphi panel who generously provided their expertise and 
experience-Dr Sumi Dunne, Dr John Delap, Dr Muireann de Paor, Dr Turlough Bolger, Dr Aoife Carroll, Dr Carol Blackburn, John Hayden, Paul Dillon, Anne Teresa Morgan, Prof Alastair Sutcliffe, Dr Dan Hawcutt, Prof Michael Shields, Dr Beth Rimmer, Dr Bill Beeby, Dr Simon Hurding, Dr Paul McCague, Dr Catherine Tuleu, Dr Sharon Conroy.

Contributors EB assisted in the compilation of the initial indicators, revised the indicators, developed the online survey, engaged the Delphi panel and drafted the manuscript. SMS conceived and supervised the study, KOB devised the initial indicators. KB extracted the prevalence data. FB provided statistical support. FM, JC, PR, CMH, TF and SMS formed the project steering group and reviewed the indicators throughout the study. All members of the project steering group revised the manuscript.

Funding This study was partly funded by the HRB Centre for Primary Care Research, funding grant HRC/2007/1 and forms part of an MSc by Research.

Competing interests None declared.

Ethics approval Royal College of Surgeons Research Ethics Committee.

Provenance and peer review Not commissioned; externally peer reviewed.

Data sharing statement Additional data including Delphi panel comments are available by request from the corresponding author.

Open Access This is an Open Access article distributed in accordance with the Creative Commons Attribution Non Commercial (CC BY-NC 4.0) license, which permits others to distribute, remix, adapt, build upon this work noncommercially, and license their derivative works on different terms, provided the original work is properly cited and the use is non-commercial. See: http:// creativecommons.org/licenses/by-nc/4.0/

\section{REFERENCES}

1. Catford JC. Quality of prescribing for children in general practice. BMJ 1980;280:1435-7.

2. Use of medicines in children. NMIC Bulletin 2009;15:2.

3. Mangione-Smith R, DeCristofaro $\mathrm{AH}$, Setodji $\mathrm{CM}$, et al. The quality of ambulatory care delivered to children in the United States. $N$ Eng J Med 2007;357:1515-23.

4. Gill PJ, Goldacre MJ, Mant D, et al. Increase in emergency admissions to hospital for children aged under 15 in England, 1999-2010:national database analysis. Arch Dis Child 2013;98:328-34.

5. O'Connor MN, Gallagher P, O'Mahony D. Inappropriate prescribing: criteria, detection and prevention. Drugs Aging 2012;29:437-52.

6. Spinewine A, Schmader KE, Barber N, et al. Appropriate prescribing in elderly people: how well can it be measured and optimised? Lancet 2007:370:173-84.

7. Kaufmann CP, Tremp R, Hersberger KE, et al. Inappropriate prescribing: a systematic overview of published assessment tools. Eur J Clin Pharmacol 2014;70:1-1.

8. Beers $\mathrm{MH}$. Explicit criteria for determining potentially inappropriate medication use by the elderly. An update. Arch Intern Med 1997;157:1531-6.

9. Gallagher P, Ryan C, Byrne S, et al. STOPP (Screening Tool of Older Person's Prescriptions) and START (Screening Tool to Alert doctors to Right Treatment). Consensus validation. Int J Clin Pharmacol Ther 2008;46:72-83.

10. Sayal K, Amarasinghe M, Robotham S, et al. Quality standards for child and adolescent mental health in primary care. BMC Fam Prac 2012;13:51.
11. Nordly S, Jorgensen $\mathrm{T}$, Andreasen $\mathrm{AH}$, et al. Quality of diabetes management in children and adolescents in Denmark. Diabet Med 2003;20:568-74.

12. Prot-Labarthe S, Weil T, Angoulvant F, et al. POPI (Pediatrics: Omission of Prescriptions and Inappropriate prescriptions): development of a tool to identify inappropriate prescribing. PLoS ONE 2014:9:e101171.

13. Gill PJ, O'Neill B, Rose $P$, et al. Primary care quality indicators for children: measuring quality in UK general practice. $\mathrm{Br} J$ Gen Pract 2014;64:e752-7.

14. Giesen P, Willekens M, Mokkink H, et al. Out-of-hours primary care: development of indicators for prescribing and referring. Int J Qual Health Care 2007;19:289-95.

15. Stang AS, Straus SE, Crotts J, et al. Quality indicators for high acuity pediatric conditions. Pediatrics 2013;132:752-62.

16. Dalleur O, Boland B, De Groot A, et al. Detection of potentially inappropriate prescribing in the very old: cross-sectional analysis of the data from the BELFRAIL observational cohort study. BMC Geriatr 2015;15:156.

17. Andersen $\mathrm{M}$. Is it possible to measure prescribing quality using only prescription data? Basic Clin Pharmacol Toxicol 2006;98:314-19.

18. Veninga CC, Denig P, Pont LG, et al. Comparison of indicators assessing the quality of drug prescribing for asthma. Health Serv Res 2001;36:143-61.

19. Campbell SM, Cantrill JA. Consensus methods in prescribing research. J Clin Pharm Therap 2001;26:5-14.

20. Avery AJ, Dex GM, Mulvaney C, et al. Development of prescribing-safety indicators for GPs using the RAND Appropriateness Method. Br J Gen Prac 2011;61:e526-36.

21. de Villiers MR, de Villiers PJ, Kent AP. The Delphi technique in health sciences education research. Med Teach 2005;27: 639-43.

22. British National Formulary for Children. 2015. https://www. medicinescomplete.com/mc/bnfc/current/. (accessed Mar 2016).

23. Cock-Wall A, Wall B, Gilbert J. Irish medicines formulary. 16th edn Dublin, Ireland: Meridian Publishing Company, 2014.

24. Jamieson S. Likert scales: how to (ab)use them. Med Educ 2004;38:1217-18

25. Sturkenboom MCJM, Verhamme KM, Nicolosi A, et al. Drug use in children: cohort study in three European countries. BMJ 2008;337: a2245.

26. Cooper JA, Ryan C, Smith SM, et al. The development of the PROMPT (PRescribing Optimally in Middle-aged People's Treatments) criteria. BMC Health Serv Res 2014;14:484.

27. Marriott J, Stehlik P. A critical analysis of the methods used to develop explicit clinical criteria for use in older people. Age Ageing 2012;41:441-50.

28. Waggoner J, Carline JD, Durning SJ. Is there a consensus on consensus methodology? Descriptions and recommendations for future consensus research. Acad Med 2016;91:663-8.

29. Guyatt GH, Oxman AD, Vist GE, et al. GRADE: an emerging consensus on rating quality of evidence and strength of recommendations. BMJ 2008;336:924-6.

30. Shelton PS, Fritsch MA, Scott MA. Assessing medication appropriateness in the elderly: a review of available measures. Drugs Aging 2000;16:437-50.

31. Mercer SW, Watt GC. The inverse care law: clinical primary care encounters in deprived and affluent areas of Scotland. Ann Fam Med 2007;5:503-10.

32. Clyne B, Smith SM, Hughes CM, et al. Effectiveness of a multifaceted intervention for potentially inappropriate prescribing in older patients in primary care: a cluster-randomized controlled trial (OPTI-SCRIPT Study). Ann Fam Med 2015;13:545-53. 